\title{
Nutritional Status and Causes of Anterior Cruciate Ligament Injury in Relation with Exercise Habit Among Patients of a Tertiary Care Hospital
}

\author{
Khandker Masum Muktadir \\ Md Monoarul Haque ${ }^{2 *}$ \\ Shuhana Sultana ${ }^{3}$ \\ Nadira Usmani ${ }^{4}$ \\ Md Nazmus Sakib ${ }^{5}$ \\ Mst Mostary Zannath
}

\begin{abstract}
'Department of Health Promotion and Health Education Bangladesh Institute of Health Sciences under Bangabandhu Sheikh Mujib Medical University (BSMMU)
\end{abstract} Dhaka, Bangladesh.

${ }^{2}$ Department of Community Nutrition Faculty of Public Health

Bangladesh University of Health Sciences

Dhaka, Bangladesh.

${ }^{3}$ Department of Health Promotion and Health Education Bangladesh University of Health Sciences Dhaka, Bangladesh.

${ }^{4}$ Department of Physical Therapy

Square Hospitals Ltd

Dhaka, Bangladesh.

${ }^{5}$ Department of Physiotherapy

Apollo Hospital

Dhaka, Bangladesh.

${ }^{6}$ Department of Public Health

Atish Dipanker University of Science \& Technology Dhaka, Bangladesh.

*Correspondence to:

\section{Md Monoarul Haque}

Fellow, Dept of Community Nutrition, Faculty of Public Health, Bangladesh University of Health Sciences, 125/1, Darus Salam, Mirpur,

Dhaka-1216, Bangladesh.

Mobile: +88 01915839550

E-mail: monoarmunna@yahoo.com

\begin{abstract}
Background: ACL injuries, is a serious problem in sports. Treatment of ACL injury is costly and it often takes 12 months or more to return to sports or in worst case and lead to early retirement. The long term outcome is also concerning issue. Objective: The goal of this study was to identify the nutritional status and causes of injury in relation with exercise habit among the patients with anterior cruciate ligament injury. Methods: A cross-sectional descriptive study was carried out in a super specialty modern tertiary care level hospital in Dhaka, Bangladesh. Total 63 samples were collected purposively to conduct this study. Data were collected through face to face interview by pretested semi-structured questionnaire and anthropometry was measured by standard technique. Prior data collection written consent was taken from the respondents. Descriptive as well as inferential statistics were used for data analysis. Results: The mean age $( \pm \mathrm{SD})$ of the respondents was $27.52( \pm 7.59)$ years where $95.3 \%$ were male patients and $4.7 \%$ were female patients. Regarding their nutritional status, $23.8 \%, 55.6 \%$ and $20.6 \%$ were normal, over weight and obese respectively. Moreover $61.9 \%$ respondents had regular exercise habit whereas $38.1 \%$ respondents had no regular exercise habit. Besides there was no significant association $(p>0.05)$ found between causes of injury and types of injury with exercise habit. Conclusion: Most of the patients were over nourished and no significant association was found between vehicle used and causes of injury. Further large scale study is needed to get actual picture.
\end{abstract}

Key words: Nutritional Status; Exercise Habit; ACL Injury.

\section{INTRODUCTION}

The anterior cruciate ligament (ACL) is one of the most common injury prone ligaments of the knee joint. The incidence of ACL injuries is currently estimated at approximately 200,000 per year and 100,000 ACL reconstructions performed per year ${ }^{1}$. The primary anatomical and structural factors examined relative to ACL injury include ACL morphology, tibial and femoral surface geometry, knee-joint laxity and lower limb structural alignments. Most of what is known is based on sex comparisons and females greater susceptibility to ACL trauma ${ }^{2}$. It is estimated that 70 percent of ACL injuries occur through non-contact mechanisms where as 30 percent result from direct contact in sports ${ }^{1}$.

The ACL database was initiated in 1990 to identify demographic, anthropometric and mechanistic variables associated with intra-articular injury. Height best predicted tibial and patellar damage. Body Mass Index (BMI) better predicted medical femoral condyle lesions, whereas weight better predicted lateral and patellofemoral injury ${ }^{3}$.

ACL injuries, is a serious problem in sports. Treatment of ACL injury is costly and it often takes 12 months or more to return to sports or in worst case and lead to early retirement. The long term outcome is also concerning issue. A majority of athletes will develop osteoarthritis within 15 to 20 years after an ACL injury. A recent literature review had been found in 23 studies that female football players have 2 to 3 times higher ACL injury risk compared to their male counterparts. Females also tend to sustain an ACL injury at younger age than male ${ }^{4}$. 
ACL injury occurs for two reasons: the failure load of the ligament and the mechanical loadlapplied to it. Female ACLs will fail at relatively lower loads than males, and female's pelvic anatomy also predisposes women to higher mechanical loads on the knee. The combination of these factors leads to increased four to six times ACL tear for female than males 5 . ACL tear can also happen in older individuals through slips and falls and more commonly seen in over 40 years of age ${ }^{6}$. To identify socio-demographic characteristics, nutritional status and causes of ACL injury among the patients with ACL tear was my ultimate goal.

\section{MATERIALS \& METHODS}

Study design: This study was a cross-sectional hospital based study.

Study population: Patients were those who attending for the treatment of ACL injury in Apollo Hospitals Dhaka.

Inclusion criteria: Patients with ACL injury undergoing reconstruction surgery and Physiotherapy treatment (Rehabilitation) and age 16+years or skeletally mature.

Exclusion criteria: History of damage to structures in addition to the ACL. If they had history of rheumatological, neurological, cardiovascular or congenital conditions affecting the lower limbs.

Sample Size: Sampling was designed on the basis of the availability of patients in the study place. As there was no previous study and scarcity of sample as well as time constrain I had to take 63 samples.

Sampling technique: Samples were allocated purposively

Study Place: Knee Centre, Apollo Hospitals Dhaka

Study period: From January 2013 to December 2013

Data collection technique: Face to face interview

Data collection Instrument: Pre-tested semi structured questionnaires, height and weight measuring machine and BMI was determined according WHO cut off value for Asian people ${ }^{7}$

Method of data analysis: All interviewed patients were coded and entered into the computer using SPSS 11.5 version of computer technology for data entry and analysis. Data were checked and rechecked by researcher himself thoroughly. Data were presented tabular as well as graphical form.

Ethical consideration: Permission was taken from the research committee of Bangladesh Diabetic Samity (BADAS). Permission was also taken from authority of Apollo Hospitals Dhaka.

\section{RESULTS}

Demographic characteristics of respondents were summarized in table 01. Maximum respondents (22.2\%) were in 26-30 years age group and the mean age $( \pm \mathrm{SD})$ of the respondents was $27.52( \pm 7.59)$ years. Male and female distribution was $95.3 \%$ and $4.7 \%$ respectively. In terms of occupation $42.8 \%, 30.2 \%$, $19.0 \%, 4.8 \%$ and $3.2 \%$ were student, service holder, businessmen, house wife and armed forces personnel respectively. Besides SSC, HSC, graduate and post graduate were $4.8 \%, 36.5 \%, 34.9$ and $23.8 \%$ respectively.
Table 1 : Distribution of the respondents according to their socio-demographic status $(n=63)$

\begin{tabular}{|c|c|}
\hline Characteristics & n $(\%)$ \\
\hline \multicolumn{2}{|l|}{ Age in years } \\
\hline Mean $( \pm \mathrm{SD})$ & $27.52( \pm 7.59)$ \\
\hline Minimum & 16 \\
\hline Maximum & 46 \\
\hline Range & 30 \\
\hline \multicolumn{2}{|l|}{ Age group in years } \\
\hline$(16-20)$ years & $13(20.6)$ \\
\hline$(21-25)$ years & $12(19.0)$ \\
\hline$(26-30)$ years & $14(22.2)$ \\
\hline$(31-35)$ years & $13(20.6)$ \\
\hline$(36-40)$ years & $7(11.1)$ \\
\hline$(41-45)$ years & $3(4.8)$ \\
\hline$\geq 46$ years & $1(1.6)$ \\
\hline \multicolumn{2}{|l|}{ Sex } \\
\hline Male & $60(95.3)$ \\
\hline Female & $3(4.7)$ \\
\hline \multicolumn{2}{|l|}{ Occupation } \\
\hline Service & $19(30.2)$ \\
\hline Armed forces personnel & $2(3.2)$ \\
\hline Student & $27(42.8)$ \\
\hline Business & $12(19.0)$ \\
\hline Housewife & $3(4.8)$ \\
\hline \multicolumn{2}{|l|}{ Education } \\
\hline Master's Degree and above & $15(23.8)$ \\
\hline Bachelor Degree/ Graduate & $22(34.9)$ \\
\hline HSC/A Level & $23(36.5)$ \\
\hline SSC/O Level & $3(4.8)$ \\
\hline
\end{tabular}

Results were expressed as number and percentage

This figure showed that most of the respondents $(61.9 \%)$ belonged to upper middle income group (21301-65800), 15.9\% were high income group $(>65801)$ and $19 \%$ were lower middle income group (5001-21300) and 3.2\% were lowest income group according to 2006 Gross National Income (GNI) per capita and using the calculation of World Bank ${ }^{8}$.

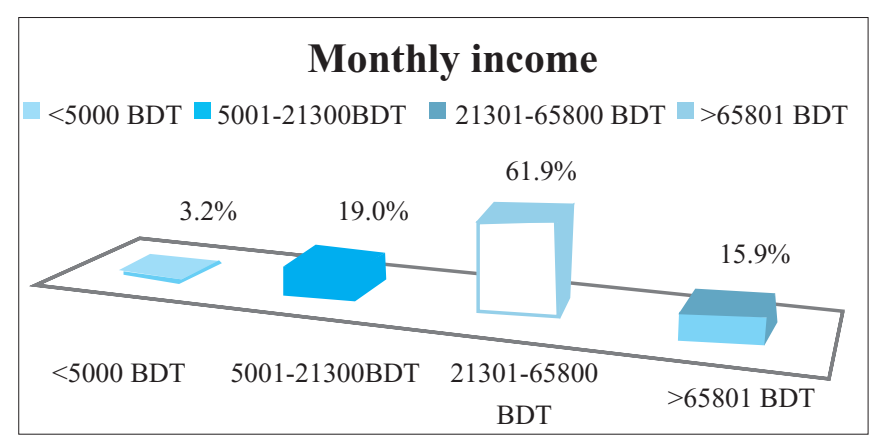

Figure 1 : Distribution of the respondents by monthly family income $(\mathrm{n}=63)$

Morethan half of the respondents $55.6 \%$ were over weight, $20.6 \%$ respondents were obese and $23.8 \%$ respondents were in normal BMI among the total 63 patients. 


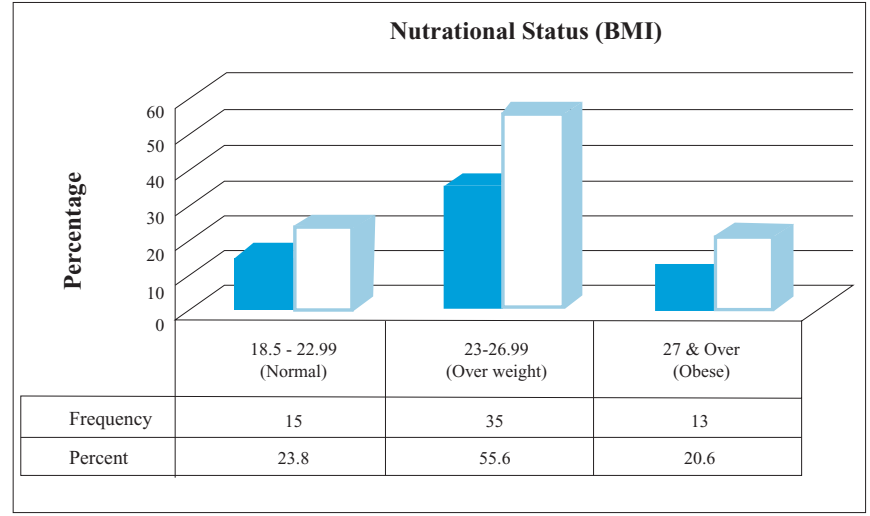

Figure 2: Distribution of the respondents according to nutritional status (n=63)

Table 2 showed that $61.9 \%$ respondents had regular exercise habit and their mean $0.421 \mathrm{SD} \pm 0.345$ whereas $38.1 \%$ respondents had no regular exercise habit with their mean 0.494 , $\mathrm{SD} \pm 0.443$. This table revealed that there was no significant association found between causes of injuries and types of injury in relation with exercise habit $2 / p=10.482 / 0.163(p=>0.05)$.

Table 2: Ratio statistics for causes of injury/ type of injury with exercise habit $(n=63)$

\begin{tabular}{lllllll}
$\begin{array}{l}\text { Exercise } \\
\text { Habit }\end{array}$ & $\begin{array}{l}\text { Frequency } \\
\text { (Percentage) }\end{array}$ & $\begin{array}{l}\text { Weighted } \\
\text { Mean }\end{array}$ & $\begin{array}{l}\text { Std. } \\
\text { Mean }\end{array}$ & Deviation & $\begin{array}{l}\text { Coefficient } \\
\text { of Dispersion }\end{array}$ & $\begin{array}{l}\text { Coefficient } \\
\text { of Variation } \\
\text { (Median } \\
\text { Centered) }\end{array}$ \\
Yes & $39(61.9)$ & 0.421 & 0.351 & 0.345 & 0.815 & $129.8 \%$ \\
No & $24(38.1 \%)$ & 0.494 & 0.380 & 0.443 & 0.810 & $141.7 \%$ \\
Overall & $63(100 \%)$ & 0.449 & 0.362 & 0.383 & 0.743 & $120.1 \%$ \\
\hline
\end{tabular}

Chi-square test were performed between exercise habit with types of injuries

$\chi^{2} / \mathrm{p}=10.482 / 0.163$ and exercise habit with causes of injuries $\chi^{2} / \mathrm{p}=2.414 / 0.660$.

Figure 3 showed that $26 \%$ had total ACL tear, $41 \%$ had total ACL tear with medial miniscus injury, $13 \%$ ACL total tear with lateral miniscus injury, $13 \%$ comples injury and only $2 \%$ had partial ACL tear with lateral miniscus injury among the respondents who had regular exercise habit. On the other hand $8 \%$ respondents had partial ACL tear, 13\% total ACL tear, $13 \%$ ACL partial tear with medial miniscus injury, 38\% ACL total tear with medial miniscus injury, $17 \%$ ACL total tear with lateral miniscus injury and $8 \%$ had complex injury among the respondents who had no regular exercise habit.

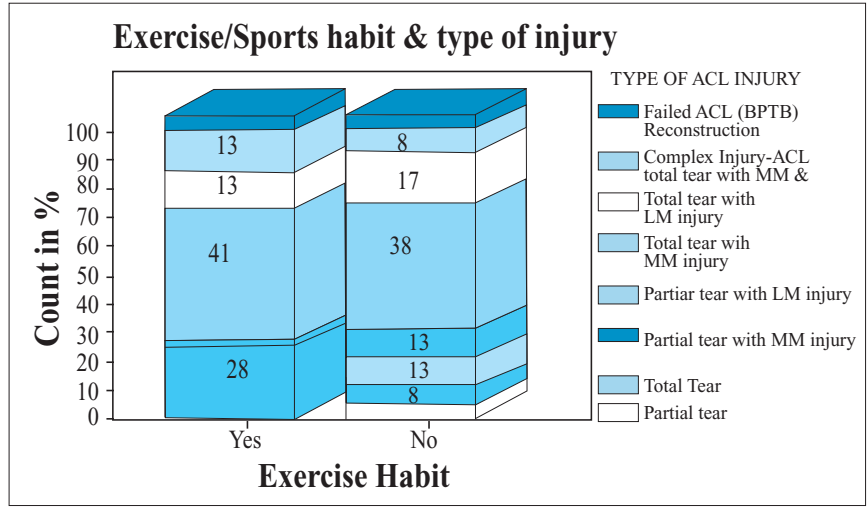

Figure 3 : Distribution between regular exercise/sports activity habit and injury type of the respondents $(n=63)$

ACL injury with history of twisting was only two patients. These result also shows there were no significant relationship between causes of ACL injury and type of vehicle used $2 / \mathrm{p}=15.19 / 0.76,(\mathrm{p}<0.05)$.

Table 3 : Association between vehicles used and causes of injury $(n=63)$

\begin{tabular}{|c|c|c|c|c|c|c|c|c|}
\hline \multirow[t]{2}{*}{$\begin{array}{l}\text { Causes } \\
\text { of Injury }\end{array}$} & \multicolumn{7}{|c|}{$\begin{array}{c}\text { Type of Vehicle use } \\
\mathrm{N}(\%)\end{array}$} & \multirow[b]{2}{*}{$\chi_{2} / p$} \\
\hline & Rickshaw & Carl/Jeep & Bus & Bi-cycl & Motorycle & Others & Total & \\
\hline $\begin{array}{l}\text { Sports injury/ } \\
\text { Sustained } \\
\text { trauma in sports }\end{array}$ & $14(36.8)$ & $11(28.9)$ & $8(21.1)$ & $1(2.6)$ & $4(10.5)$ & $0(0)$ & $38(100.0)$ & 15.190 .76 \\
\hline $\begin{array}{l}\text { RTA } \\
\text { Fall from height/ }\end{array}$ & $4(23.5)$ & $2(11.8)$ & $5(29.4)$ & $0(0)$ & $5(29.4)$ & $1(5.9)$ & $17(100.0)$ & \\
\hline $\begin{array}{l}\text { Accidental } \\
\text { fall }\end{array}$ & $2(50.0)$ & $1(25.0)$ & $1(25.0)$ & $0(0)$ & $0(0)$ & $0(0)$ & $4(100.0)$ & \\
\hline Twisting injury & $0(0)$ & $0(0)$ & $1(50.0)$ & $0(0)$ & $1(50.0)$ & $0(0)$ & $2(100.0)$ & \\
\hline Others & $0(0)$ & $1(50.0)$ & $0(0)$ & $0(0)$ & $1(50.0)$ & $0(0)$ & $2(100.0)$ & \\
\hline Total & $20(31.7)$ & $15(23.8)$ & $15(23.8$ & $1(1.6)$ & $11(17.5)$ & $1(1.6)$ & $63(100.0)$ & \\
\hline
\end{tabular}

A cross-tabulation was performed where $2 / p=15.19 / 0.76,(p<0.05)$

\section{DISCUSSION}

The recent practice trend in the physical therapy profession has been "evidence-based practice." Sample size was sixty-one individuals with acute ACL tears ( 21 females, 40 males) with a mean age of $26.03 \pm 7.99$ years (range, 14-47 years) ${ }^{9}$. Another Study were shown that eighty-four patients ( $86 \%$ males; overall mean age $=39$ years, $\mathrm{SD}=9$, range $=21-58$; female mean age $=39$ years, $\mathrm{SD}=9$, range $=24-58$; male mean age $=40, \mathrm{SD}=9$, range $=21-58)^{10}$. Whereas in this study the mean age and $( \pm \mathrm{SD})$ of the respondents was $27.52( \pm 7.59)$. The age range were minimum 16 and maximum 46. Among the total respondents of 63 , male and female was $60(95.3 \%)$ and only $3(4.7 \%)$ respectively. A study was conducted to compare functional out comes after primary hamstring-graft anterior cruciate ligament reconstruction in patients with body mass index (BMI) classes. They reviewed 92 patients among them 49 were normal BMI and 43 were high BMI. 
Results showed that there were no significant differences between the groups in pre and post operative ligament laxity; whereas high BMI group had slightly increased post operative complication rather than normal BMI group ${ }^{11}$. From the present study we found that there were no significant association between BMI category and causes of ACL injury $\chi^{2} / \mathrm{p}=$ $4.31 / 0.828(\mathrm{p}=<0.05)$. More than half of the respondents $55.6 \%$ were over weight, $20.6 \%$ respondents were obese and only $23.8 \%$ respondents were in normal BMI. Mean and SD of BMI was $2.97( \pm 0.61)$. Sports injury were common cause of ACL injury and the most of the non-contact ACL injuries occurred during sudden twisting motion. Other common causes of ACL injuries occurred fall from bike and motor bike ${ }^{12}$. Whereas common causes of ACL injury in this study were $60.32 \%$ from sports injury that was the main cause responsible for more than half of the ACL injury, 27\% ACL injury occurred from RTA, $6.34 \%$ ACL injury occurred from fall and twisting were responsible only $3.17 \%$ of ACL tear.

\section{ACKNOWLEDGEMENT}

No funding was provided to carry out this study. It was a joint research effort of Physiotherapists and Public Health Specialists. I would like to gratefull to Dr. M. Ali, Senior Consultant and Coordinator, Knee Centre, Apollo Hospitals Dhaka for giving kind permission to collected data from his patients with ACL injury. At last but not least my special thanks to DM Nurul Amin Utpal, Physiotherapist, Apollo Hospitals, Dhaka for his enormous support.

\section{CONCLUSION}

This study identified that most of the respondents were overnourished and there were no significant relationship between causes of injury and type of injury with regular exercise habit. Besides no significant association was seen among vehicle used and causes of ACL injury. Further large scale study was needed and this study result should not be generalize.

\section{DISCLOSURE}

All the authors declared no competing interest.

\section{REFERENCES}

1. Fonseca F, “ACL Injury: Does It Require Surgery?” OrthoInfo, American Academy of Orthopaedic Surgeons. http://orthinfo.aaos.org/topic.cfm?topic=A00297\&webid=23DAE556 (Accessed date-28.03.2014)

2. Sandra J Shultz, Randy J Schmitz, Anne Benjaminse, Ajit M Chaudhari, Malcolm Collins and Darin A Pauda, ACL Research Retreat VI: An update on ACL Injury Risk and Prevention. J Athl Train. 2012; 47(5):591-603. [PMCID: PMC3465040]

3. Browers AL, et al, "Height, weight and BMI predict intra-articular injuries observed during ACL reconstruction: evaluation of 456 cases from a prospective ACL database". Clin J Sport Med. 2005; 15(1):9-13.

4. Steffen K, Myklebust G and Bhar R, "Injury Prevention In Female Football”. Aspetar Sports Medical Jurnal. www.aspetar.com/journal/viewarticle.aspx?id=82 (accessed date 09.04.2014)

5. Slauterbeck JR, Hickox JR, Beynnon B and Hardy DM, “Anterior Cruciate Ligament Biology and Its Relationship to Injury Forces”. Orthop Clin N Am.2006; 37:585-591

6. Anterior cruciate ligament injury en.m.wikipedia.org/wiki/Anterior_cruciate_ligament_injury (Last accessed date 09.04.2014)

7. World Health Organization expert consultation. Appropriate body mass index for Asian populations and its implications for policy and intervention strategies. Lancet. 2004;363(9403):157-163.

8. Haque ANMN: By the numbers: The middle-income matrix. The Daily Star Editorial. Date 18.11.2007.

9. Britton W. Brewer; Allen E. Cornelius; Judy L. Van Raalte; Albert J. Petitpas; Joseph H. Sklar; Mark H. Pohlman; Robert J. Krushell and Terry D. Ditmar,"Age-Related Differences in Predictors of Adherence to Rehabilitation after Anterior Cruciate Ligament Reconstruction". Journal of Athletic Training. 2003;38(2):158-162, by the National Athletic Trainers' Association, Inc. www.journalofathletictraining.org

10. Peter C Goodwin, Matthew C Morrissey, Rumana Z Omar, Michael Brown, Kathleen Southall and Thomas B McAuliffe, "Effectiveness of Supervised Physical Therapy in the Early Period After Arthroscopic Partial Meniscectomy- Controversy exists about the effectiveness of physical therapy after arthroscopic partial meniscectomy”. Phys Ther.2003; 83(6):52035.[PMID:14519065]. www.ncbi.nlm.nih.gov/pubmed/12775198 (Accessed date 28.03.14)

11. Moez S. B.,Yousaf K.,Graham H, Alison H, Stepen C, Michal J. M, Functional outcome of primary hamstring anterior cruciate ligament reconstruction in patient with different body mass index classes. Arthroscopic and related surgery, 2013; 29: 8.

12. About ACL- what is an ACL injury causes. www.knee.in/ACL.htm (Last accessed date 08.04.2014) 